\title{
Identification of functional SNPs in the 5-prime flanking sequences of human genes
}

\author{
Salim Mottagui-Tabar*1, Mohammad A Faghihi' ${ }^{1}$, Yosuke Mizuno1, \\ Pär G Engström ${ }^{1}$, Boris Lenhard ${ }^{1}$, Wyeth W Wasserman ${ }^{2}$ and \\ Claes Wahlestedt ${ }^{1}$
}

\begin{abstract}
Address: ${ }^{1}$ Center for Genomics and Bioinformatics, Karolinska Institutet, SE-17177 Stockholm, Sweden and ${ }^{2}$ Centre for Molecular Medicine and Therapeutics, University of British Columbia, Vancouver, BC V5Z 4H4, Canada

Email: Salim Mottagui-Tabar* - salim.mottagui-tabar@cgb.ki.se; Mohammad A Faghihi - mohammad.ali.faghihi@cgb.ki.se; Yosuke Mizuno - yosuke.mizuno@cgb.ki.se; Pär G Engström - par.engstrom@cgb.ki.se; Boris Lenhard - boris.lenhard@cgb.ki.se; Wyeth W Wasserman - wyeth@cmmt.ubc.ca; Claes Wahlestedt - claes.wahlestedt@cgb.ki.se

* Corresponding author
\end{abstract}

Published: 17 February 2005

BMC Genomics 2005, 6:18 doi:10.1186/147|-2164-6-18

This article is available from: http://www.biomedcentral.com/I47/-2/64/6//8

(c) 2005 Mottagui-Tabar et al; licensee BioMed Central Ltd.

This is an Open Access article distributed under the terms of the Creative Commons Attribution License (http://creativecommons.org/licenses/by/2.0), which permits unrestricted use, distribution, and reproduction in any medium, provided the original work is properly cited.
Received: 02 November 2004

Accepted: 17 February 2005

\begin{abstract}
Background: Over 4 million single nucleotide polymorphisms (SNPs) are currently reported to exist within the human genome. Only a small fraction of these SNPs alter gene function or expression, and therefore might be associated with a cell phenotype. These functional SNPs are consequently important in understanding human health. Information related to functional SNPs in candidate disease genes is critical for cost effective genetic association studies, which attempt to understand the genetics of complex diseases like diabetes, Alzheimer's, etc. Robust methods for the identification of functional SNPs are therefore crucial. We report one such experimental approach.
\end{abstract}

Results: Sequence conserved between mouse and human genomes, within 5 kilobases of the 5prime end of 176 GPCR genes, were screened for SNPs. Sequences flanking these SNPs were scored for transcription factor binding sites. Allelic pairs resulting in a significant score difference were predicted to influence the binding of transcription factors (TFs). Ten such SNPs were selected for mobility shift assays (EMSA), resulting in 7 of them exhibiting a reproducible shift. The full-length promoter regions with 4 of the 7 SNPs were cloned in a Luciferase based plasmid reporter system. Two out of the 4 SNPs exhibited differential promoter activity in several human cell lines.

Conclusions: We propose a method for effective selection of functional, regulatory SNPs that are located in evolutionary conserved 5-prime flanking regions (5'-FR) regions of human genes and influence the activity of the transcriptional regulatory region. Some SNPs behave differently in different cell types.

\section{Background}

Single nucleotide polymorphisms (SNPs) are the most common form of genomic variations occurring on average every 1000 nucleotides. The vast majority of SNPs are neutral allelic variants, however the few that do influence a phenotype in a measurable way, are important for 
understanding the underlying genetics of human health. SNPs are the focus of a large number of human genetics studies attempting to understand their impact on complex diseases like Alzheimers, Parkinsons, diabetes, etc. Most SNPs, by the virtue of their location within genes (introns, 3'-UTRs, etc) or between genes, are considered most likely to be benign and not to contribute to a phenotype, whether it may be the manifestation of a disease or quicker metabolism of a drug. Among the group of SNPs located within coding regions of genes and causing a change in the peptide sequence (non-synonymous SNPs or 'nsSNPs') or among SNPs located within promoters (regulatory SNPs or rSNPs), a majority may not influence the overall activity of the protein or the gene expression. With the per-SNP validation and genotyping cost relatively high, it is increasingly important to develop strategies to predict functionally relevant SNPs in silico. The SNP databases in public domain, like NCBI/dbSNP and HGVbase, have facilitated this by highlighting all nsSNPs and also further classifying the location of the amino acid within the encoded proteins [1] to more accurately predict the detrimental effects of a change in peptide sequence. Several recent studies have attempted to focus on the subset of nsSNPs that most likely influence phenotype [2-6]. Of the approximately 4.5 Million SNPs in dbSNP [7], an estimated 10,000 nsSNP exist and approximately 10-15\% of those are projected to be damaging [6]. Comparatively fewer attempts have been made to predict and validate functional promoter SNPs [8].

Transcriptional regulatory regions in the 5 '-FR of human genes encode short (often $<25$ bp) $[9,10]$ sequences which serve as targets for binding of transcription factors (TFs). Understanding the conditions of binding, specificity and identity of the factors would help us understand the mechanism of regulation of human genes. Eukaryotic TFs tolerate considerable sequence variation in their target sites and recent bioinformatics works [11-13] have developed methods to model the DNA binding specificity of individual TFs [10]. Such matrices, although highly accurate $[9,14]$, are less specific in the identification of sites with in vivo function [11], mainly due to our limited understanding of additional factors involved in TF specificity such as factor cooperative binding, protein-protein interactions, chromatin superstructures and TF concentrations. Currently the most successful approach to overcome this information gap is based on the assumption that sequences conserved between species (here human and mouse) would most likely mediate biological function [15-19].

The 7TM (7 trans-membrane domain proteins), also known as the hetero-trimeric GTP-binding protein (G protein)-coupled receptors (GPCRs) are members of a large family with an estimated 700 genes in the human genome [20]. By some estimates, nearly $60 \%$ of drugs marketed today target directly or indirectly the GPCR family members [21]. Several studies have collectively analyzed the occurrence, and importance, of coding SNPs to pharmaceutical efforts, in this family of genes [22-24]. Characterizing polymorphisms that are located in the 5'FR of these genes and that influence expression has been reported earlier. We therefore selected a subset of clinically and pharmacologically important GPCR genes and their 5'-FR sequences to test our bioinformatics and laboratory experimentation approach for prediction of functionally important SNPs in regulatory regions. Our selection system evaluates the influence of SNPs on TFDNA complex stability, and further investigates the influence of such SNPs on promoter activity. We present a proof-of-concept for such a strategy and identify issues and problem-areas for future developments.

\section{Results}

The lists of the full names and Ensembl ENSG numbers [25] of the 176 GPCR genes are shown in additional files [See Additional file 1]. From a total of approximately 800 SNPs in proximal $5 \mathrm{~kb}$ regions, less than 200 were mapped to regions of mouse-human genome conservation. Of these approximately 200 SNPs, 36 were predicted to influence TF binding, in regions of sequence conservation of over $70 \%$ in human-mouse; the alignments for two such regions are indicated in additional files [See Additional file 2]. Table 1 lists the 21 genes, along with the SNPs, TFs and TFBS sequences and positions relative to transcription start site. These 36 candidate SNPs in Table 1 were qualified by our selection criteria, as described in the methods section, and were predicted to influence the binding of TFs in a qualitative manner. The absolute binding score of the TF differed by at least 2 units between the two alleles. Ten SNPs within the 5'-FR of 7 genes were selected for EMSA tests and are shown in bold letters in Table 1. The choice of these genes was based on our understanding of their significance in human physiology and relevance to research interests within the GPCR research community. Table 2 shows the results from the EMSA experiments, where values in each column for Allele 1 and Allele 2 are the ratios of measurements from each of the 5 different concentrations of the competitor oligomers (labeled $\times 5$ through $\times 25$ in Table 2 and in Figure 1) divided by the measurements without competitor (labeled ' $C$ ' in Figure 1). The decrease in level of the labeled product as a consequence of increasing nonlabeled oligomer concentration is an indication of the efficiency of displacement, thereby reflecting the relative stability of the DNA-protein complex. A marginal increase in level of radio-labeled complex, instead of a decrease (Table 2 rs1800508) is generally considered to be due to additional factor involvements. Table 2, column 'Ratio' shows the difference, calculated for the highest 
A) Bradykinin rs1799722

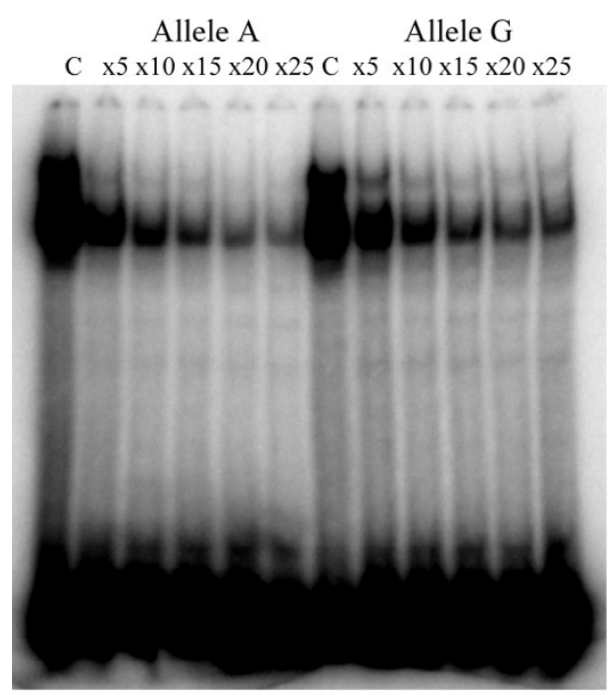

B) Calcitonin rs 2528521

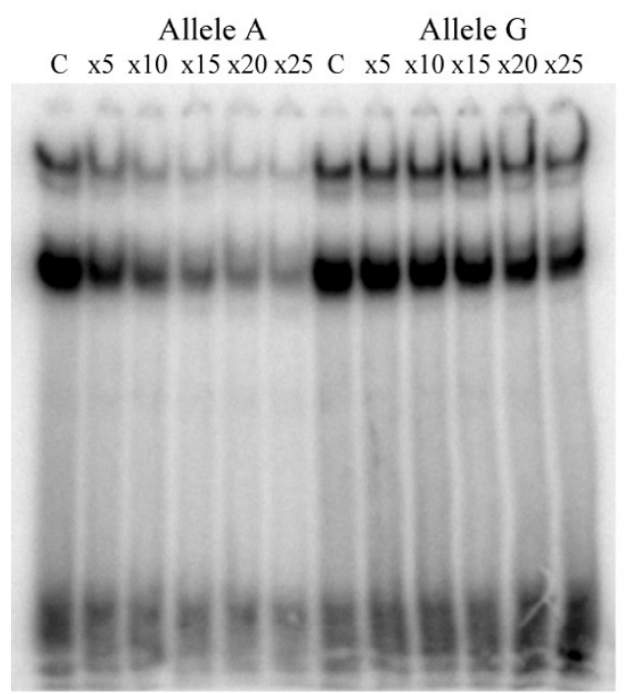

\section{Figure I}

Polyacrylamide gels from electromobility shift assays. Polyacrylamide gels showing the decrease in amounts of protein complex with labelled oligomer as the concentration of the competing non-labelled oligomer increases (lanes marked $\times 5$ through $\times 25$ ). Lane marked ' $C$ ' has no competitor and represents the basal levels of labelled complex. The measure of displacement of the labelled oligomer is expressed as a ratio of radio-labelled product, for each lane, divided by the basal value, presented in Table 2 . Comparison of allele specific DNA-protein complex stability is a ratio of the highest competitor concentration $(x 25)$ of each of the two alleles. Thus for rs 1799722 (A) allele A binds proteins 1.66 times better than allele $G$ and for rs 252852 I (B) allele $A$ binds proteins 2.62 times better than allele $G$ (Table 2, extreme right column). concentration of the non-labeled competitor (25-fold), between the efficiency of competition between a perfectmatch competitor and the allelic mismatch competitor. Values close to 1.00 indicate no difference in rate of competition between the two alleles, and therefore no relative difference in stability of the DNA-protein complex. While 4 SNPs exhibit mobility shift with a difference of 2-fold or more (rs267412, rs509813, rs945032 and rs2528521), three SNPs exhibit a moderate, nevertheless reproducible shift (rs1799722, rs2882225 and rs1538251). Finally, three SNPs fail to show any significant shift (rs968554, rs267413 and rs1800508). In all, seven out of ten polymorphic markers indicated reproducible binding differences between the alleles. Figure 1 shows pictures of EMSA gels for two of the SNPs, rs1799722 and rs2528521.

For EMSA-positive markers with no validation information at dbSNP, HGVbase or Celera Discovery Systems ${ }^{\mathrm{TM}}$ we did a validation analysis using RFLP (restriction fragment length polymorphism) on DNA samples from 25 healthy Nordic individuals. The three SNPs which failed to show positive gel-shift results (serotonin receptor 5HT-1A: rs968554; DRD1: rs267413; and BK-2: rs1800508) were not investigated any further. For dopamine receptor D1 (DRD1) polymorphism (rs267412) the genotype distribution was found to be $\mathrm{TT}=30 \%, \mathrm{AA}=20 \%$ and $\mathrm{AT}=$ $50 \%$, and for calcitonin receptor promoter (CT-R) polymorphism rs 2528521, it was $\mathrm{GG}=40 \%, \mathrm{AA}=30 \%$ and $\mathrm{GA}=30 \%$. While rs267412 was found to be in Hardy Weinberg Equilibrium (HWE), rs2528521 was not. A larger population sample should be genotyped to accurately measure HWE for both these loci. Bradykinin B2 (BK-2) promoter polymorphism rs1799722 is noted to be polymorphic (major allele C: $56 \%$ ) at NCBI/dbSNP. The polymorphic nature of this locus (rs1799722) was also confirmed by crosschecking at Celera Discovery Systems ${ }^{\mathrm{Tm}}$. Also for the second BK-2 SNP rs945032, the allele frequency information was found at dbSNP (major allele = $80 \%$ ). NCBI's dbSNP provided no allele frequency information about rs1538251 adenosine-A3 receptor (ADORA3), and on sequencing 20 DNA samples this marker proved to not be polymorphic in Nordic sample population, and was eliminated from further analysis (data not shown). The genotype frequency of muscarinic acetylcholine receptor M1 (CHRM1) SNP rs509813 was documented at Celera Discovery Systems ${ }^{\mathrm{Tm}}$. The contigposition of rs2882225 (follicle simulating hormone receptor; FSHR) was not in agreement between the three major public genome databases, i.e. NCBI, Ensembl and Santa Cruz Genome Assembly (UCSC). It was mapped within the transcript for FSHR by NCBI/dbSNP, and completely absent from Ensembl and UCSC [26]. Therefore of the seven SNPs exhibiting positive EMSA, five SNPs (in 
Table I: List of positive SNP candidates for EMSA studies. The genes and the SNPs which were tested in this report are indicated in bold text. The name of the TF and the predicted consensus site from the transcription start site are indicated.

\begin{tabular}{|c|c|c|c|c|}
\hline Gene Name /Ensembl ENSG & TF name (distance from start site) & SNP rs ID & Allele I & Allele 2 \\
\hline \multirow[t]{3}{*}{ Beta-2 adrenergic receptor ENSG00000I64272 } & $\mathrm{Nkx}(-4257)$ & rs2082382 & ttcagtg & ttcggtg \\
\hline & Gklf(-42I6) & rs2082395 & aagtgagaag & aagtgagaaa \\
\hline & c-ETS(-1049) & rs 1432622 & gatcct & gatctt \\
\hline P2y purinoceptor 5 (p2y5) ENSG00000I39679 & SAP-I (-149) & rs223357I & agcggaaat & agtggaaat \\
\hline \multirow[t]{7}{*}{ Anion exchange protein 2 ENSG00000I64889 } & Yin-Yang(-3480) & rs2069453 & gccatg & gccgtg \\
\hline & c-ETS(-2988) & rs206945I & tttccc & tgtccc \\
\hline & SPI-I(-2988) & rs206945I & gggaaa & gggaca \\
\hline & SPI-B(-2990) & rs206945I & atgggaa & atgggac \\
\hline & c-MYB_I (-1536) & rs2069442 & gggagttg & gggacttg \\
\hline & $\mathrm{Nkx}(-1537)$ & rs2069442 & tcaagtc & tcaactc \\
\hline & SPI $(-1440)$ & rs206944I & agggctggga & agagctggga \\
\hline \multirow[t]{2}{*}{ C-c chemokine receptor type I ENSG00000I63823 } & SPI-B(-II7) & rs3181080 & acaagaa & actagaa \\
\hline & SOXI7(-I18) & rs3181080 & tttcttgtc & tttctagtc \\
\hline Frizzled 6 precursor (frizzled-6) ENSG00000I64930 & deltaEFI (-629) & rs3758096 & caccta & aaccta \\
\hline \multirow[t]{2}{*}{ Proteinase activated receptor 3 ENSG00000164220 } & c-ETS(-32) & rs2069647 & catcct & cctcct \\
\hline & deltaEFI $(-3 I)$ & rs2069647 & ctcctt & atcctt \\
\hline \multirow[t]{2}{*}{ Chemokine $(\mathrm{C}-\mathrm{X}-\mathrm{C})$ receptor 6 ENSG00000163819 } & c-MYB_I (-469) & rs2234352 & tacagatg & tatagatg \\
\hline & Thing I-E47(-469) & rs2234352 & catctgtaaa & catctataaa \\
\hline \multirow{9}{*}{ 5-hydroxytryptamine la receptor ENSG00000178394 } & ARNT(-2I74) & rs968554 & caagtg & caactg \\
\hline & c-MYB_I (-2174) & rs968554 & tccagttg & tccacttg \\
\hline & deltaEFI $(-2174)$ & rs968554 & cacttg & cagttg \\
\hline & $n-M Y C(-2 \mid 74)$ & rs968554 & cacttg & cagttg \\
\hline & USF(-2I74) & rs968554 & caagtgg & caactgg \\
\hline & USF(-2175) & rs968554 & cacttgg & cagttgg \\
\hline & ARNT(-2174) & rs968554 & cacttg & cagttg \\
\hline & deltaEFI $(-2 \mid 74)$ & rs968554 & caactg & caagtg \\
\hline & $\mathrm{n}-\mathrm{MYC}(-2174)$ & rs968554 & caagtg & caactg \\
\hline \multirow[t]{4}{*}{ Muscarinic acetylcholine receptor MI ENSG00000I68539 } & MZF_I-4(-I48) & rs5098I3 & tggggg & tggcgg \\
\hline & MZF_5-13(-149) & rs509813 & gtggggggag & gtggcgggag \\
\hline & MZF_I-4(-I47) & rs509813 & gggggg & ggcggg \\
\hline & SPI $(-147)$ & rs509813 & ggggggagga & ggcgggagga \\
\hline \multirow[t]{2}{*}{ Dopamine receptor DIa ENSG00000I84845 } & FREAC- $4(-43 I I)$ & rs2674I2 & gtaaaccc & gtaagccc \\
\hline & TCFIIMafG(-4446) & rs267413 & actgac & acagac \\
\hline \multirow[t]{5}{*}{ Follicle stimulating hormone receptor ENSG00000 I 70820} & $\mathrm{HFH}-3(-8 \mathrm{I})$ & rs2882225 & ggatgctttttt & ggatgctgtttt \\
\hline & $\mathrm{HFH}-2(-82)$ & rs2882225 & gatgcttttttt & gatgctgttttt \\
\hline & c-ETS(-80) & rs2349718 & cttctt & cttttt \\
\hline & Gklf(-87) & rs 2349718 & aaaaaaaaag & aaaaaaaaaa \\
\hline & SPI-I $(-80)$ & rs2349718 & aagaag & aaaaag \\
\hline \multirow[t]{6}{*}{ 5-hydroxytryptamine 2c receptor ENSG00000I47246 } & $\mathrm{HFH}-\mathrm{I}(-1736)$ & rs3795182 & ccatgtttata & ccatatttata \\
\hline & MEF2(-I734) & rs3795182 & atatttataa & atgtttataa \\
\hline & FREAC-4(-1734) & rs3795182 & ataaacat & ataaatat \\
\hline & c-ETS(-27I) & rs3813928 & tatcct & taccct \\
\hline & $M Z F_{-} I-4(-273)$ & rs3813928 & tgagga & tgaggg \\
\hline & SPI-B(-273) & rs3813928 & tgaggat & tgagggt \\
\hline \multirow[t]{4}{*}{ Bradykinin receptor 2 ENSG00000168398 } & Ahr-ARNT(-535) & rs945032 & tgggtg & tgggta \\
\hline & $M Z F \_I-4(-80)$ & rs 1800508 & tgggca & tgagca \\
\hline & AP2alpha(-79) & rs 1800508 & gcccaggag & gctcaggag \\
\hline & TCFII-MafG $(-6 I)$ & rs 1799722 & aatgat & agtgat \\
\hline Adenosine $A 3$ receptor ENSG00000I 21933 & AP2alpha(-4276) & rs|53825 I & gccctctgg & tccctctgg \\
\hline \multirow[t]{3}{*}{ Alpha-Ia adrenergic receptor ENSG00000I 20907} & c-ETS(-4898) & rs562843 & cttctt & cttatt \\
\hline & SPI-I (-4898) & rs562843 & aagaag & aataag \\
\hline & $N k x(-4900)$ & rs562843 & ataagtt & agaagtt \\
\hline \multirow[t]{4}{*}{ C-c chemokine receptor type 2 ENSG00000I 21807} & TCFIIMafG(-I823) & rs3092964 & catgcc & catacc \\
\hline & Ahr-ARNT(-I825) & rs3092964 & tgcatg & tgcata \\
\hline & TCFIIMafG(-I823) & rs3749462 & catgcc & catacc \\
\hline & Ahr-ARNT(-I825) & rs3749462 & tgcatg & tgcata \\
\hline \multirow[t]{2}{*}{ Putative chemokine receptor ENSG00000II 9594} & SPI-B(-86) & rs3825163 & tcaggaa & ccaggaa \\
\hline & FREAC-4(-80) & rs3825163 & gtaaccat & ataaccat \\
\hline
\end{tabular}


Table I: List of positive SNP candidates for EMSA studies. The genes and the SNPs which were tested in this report are indicated in bold text. The name of the TF and the predicted consensus site from the transcription start site are indicated. (Continued)

\begin{tabular}{|c|c|c|c|c|}
\hline & TCFII-MafG(-8I) & rs3825163 & gataac & ggtaac \\
\hline & Nkx(-I6I) & rs2256572 & ttatttg & ctatttg \\
\hline & $S 8(-163)$ & rs2256572 & tatta & tacta \\
\hline & TCFI IMafG(-232) & rs590447 & gctgac & gccgac \\
\hline & deltaEFI $(-230)$ & rs590447 & cagctt & cggctt \\
\hline Calcitonin receptor ENSG00000004948 & TCFIIMafG(-5II) & rs252852I & agtgac & agtggc \\
\hline \multirow[t]{5}{*}{ Lectomedin-3 ENSG00000 I 5047I } & AP2alpha(-770) & rs905963 & gcccogagc & acccogagc \\
\hline & SPI-I (-763) & rs905963 & gcgaac & gcgagc \\
\hline & c-ETS(-365) & rsI505666 & cctcct & ccttct \\
\hline & SPI-I (-366) & rs 1505666 & gagaag & gaggag \\
\hline & $M Z F_{-} I-4(-367)$ & rs 1505666 & agagga & agagaa \\
\hline Glucagon-like P2 ENSG00000065325 & SPI-B(-88I) & rs|402655 & tgagaaa & tgataaa \\
\hline \multirow[t]{3}{*}{ G protein-coupled receptor ENSG00000I02865 } & Yin-Yang(-1 I8) & rs2240047 & gccatg & gccetg \\
\hline & TCFIIMafG(-II8) & rs2240047 & catggc & cagggc \\
\hline & Gfi(-I575) & rs724615 & aaaatcacag & aaaatgacag \\
\hline
\end{tabular}

four genes) qualified for analysis of their influence on promoter activity.

For expression analysis in living cells, the published promoter regions, or putative regulatory 5 'FR of up to $2 \mathrm{~Kb}$, were cloned and basal levels of luciferase were monitored. Repeated attempts to clone the promoter region of DRD1 failed (data not shown). Furthermore the position of rs267413 is mapped at -4446 nucleotides with respect to the transcription start site, whereas the minimum length of the genomic fragment known to drive DRD1 expression is limited to 2571 nucleotides. Considering the distal position of the marker, we decided not to examine rs267413 further in this study. The promoter regions of BK-2, CHRM1 and CT-R were cloned successfully. A total of four dissimilar human cell lines (HeLa, Hep2G and SK$\mathrm{N}-\mathrm{MC}, \mathrm{HEK} 293$ ) were used to monitor the influence of the four SNPs (rs945032, rs1799722, rs2528521 and rs509813) to investigate differences in expression that are possibly due to differences in TF expression in different cell types. BK-2 promoter SNPs rs945032 (genotype = GG) and rs1799722 (genotype = AA) showed approximately $40 \%-60 \%$ higher activity in HeLa cells as compared to their other homozygote alleles AA and GG, respectively (Figure 2). The BK-2 SNP rs945032 behaves in a reciprocal manner in two (HeLa, and HEK293) cell types. The BK-2 SNP rs1799722 allele 'C' increases expression only in HeLa while decreasing expression in the other three cell types, similar to CHRM1 marker rs509813. CTR marker rs2528521 and CHRM1 marker rs509813 failed to show any influence on luciferase expression levels in HeLa and SK-N-MC cells. Finally, the CT-R SNP rs2528521, allele ' $C$ ', influences expression in a significant manner, but only in one cell line (Hep2G). Hence, different alleles behave differently in different cell environments.

\section{Discussion}

SNPs that are located within coding regions and result in a change in the peptide sequence may be classified as 'damaging' or 'altering' if predicted to be in structurally or functionally important sites of the three dimensional structure of the protein. It is less straightforward to predict the functional importance of SNPs within regulatory regions. TFs tolerate variation in their binding sites and all positions in a site do not contribute equally to the binding energy. Therefore, the quantitative effect a given rSNP has on gene expression depends on its position and the bases involved. Complex human diseases like Parkinson's, diabetes and obesity are polygenic diseases, where many predisposing genetic and environmental factors together, over a period of time, cause a disease state. Differences in expression of genes and cellular concentrations of proteins due to common polymorphisms in 5 ' regulatory regions could equally elucidate gene function as the examination of non-synonymous SNPs in coding regions. We decided to test the 5'-FR of a group of physiologically and clinically important genes, for SNPs within TFBS, which could potentially influence the kinetics of binding affinity.

A common strategy for modeling the binding preferences of a transcriptions factor is to construct a position weight matrix (PWM) from known binding sites. PWMs are probabilistic models that capture the nucleotide preference at each position of a TFBS as well as the differential contribution of positions to the overall binding energy. When a putative binding site sequence is assessed using a PWM, a score is obtained that theoretically should be proportional to the binding energy between the TF and that sequence [10]. It has been convincingly shown, and generally accepted, that by considering DNA sequence conservation between mouse and human, the over-predictive 
Table 2: Oligonucleotide sequences used for EMSA. For every SNP, 4 oligonucleotides (2 complimentary pairs) were synthesized, one pair for each allele. One oligonucleotide sequence from each pair had additional GG dinucleotide overhangs at the 5 'end for fill-in labeling reaction. Care was taken to make sure that the additional GG-dinucleotide did not influence the predicted TF binding capability. The complementary sequences lacked the GG pairs. Only the allelic sequence predicted to bind most stably was chosen for the fill-in labeling reaction (marked*) while the gel shift assays were carried out using competitor with a perfect match versus a competitor with the allelic mismatch. The polymorphic site is underlined. Column 'Ratio' shows the difference in competition between the labeled and non-labeled oligomers at 25 -fold excess, by dividing Allele2 (x25) values by Allele I (x25).

\begin{tabular}{|c|c|c|c|c|c|c|c|c|c|c|c|c|}
\hline \multirow[t]{2}{*}{ Gene name and rs ID } & \multirow[t]{2}{*}{ Sequence } & \multicolumn{5}{|c|}{$\begin{array}{c}\text { Allele I } \\
\text { (competitor oligo is a perfect } \\
\text { match) }\end{array}$} & \multicolumn{5}{|c|}{$\begin{array}{c}\text { Allele } 2 \\
\text { (competitor oligo has a mismatch) }\end{array}$} & \multirow[t]{2}{*}{ Ratio } \\
\hline & & $\times 5$ & $x 10$ & $\times 15$ & $\times 20$ & $\times 25$ & $x 5$ & $x 10$ & $x 15$ & $\times 20$ & $\times 25$ & \\
\hline $\begin{array}{l}\text { Serotonin receptor }(5-\mathrm{HT}-\mathrm{IA}) \\
\text { rs } 968554 \text { ENST00000323865 }\end{array}$ & $\begin{array}{l}\text { GGAAAAGAATCCA } \\
\text { CTTGGGCCAATG * } \\
\text { GGAAAAGAATCCA } \\
\text { GTTGGGCCAATG }\end{array}$ & 1.29 & - & 1.27 & 1.23 & 1.00 & 1.16 & - & 1.12 & 1.13 & 0.96 & 0.96 \\
\hline $\begin{array}{l}\text { Dopamine receptor DRDI rs } 267412 \\
\text { ENST00000329|44 }\end{array}$ & $\begin{array}{l}\text { GGAATGTAAACCC } \\
\text { AACACAAAAG * } \\
\text { GGAATGTAAGCCC } \\
\text { AACACAAAAG }\end{array}$ & 0.72 & - & - & 0.54 & 0.56 & 0.98 & - & 1.06 & 1.03 & 1.12 & 2.05 \\
\hline $\begin{array}{l}\text { Dopamine receptor DRDI rs } 267413 \\
\text { ENST00000329|44 }\end{array}$ & $\begin{array}{l}\text { GGTATAAAAGTCA } \\
\text { GTGAATACAG * } \\
\text { GGTATAAAAGTCI } \\
\text { GTGAATACAG }\end{array}$ & 0.96 & - & 0.81 & 0.74 & 0.81 & 0.97 & - & 0.98 & 0.97 & 1.01 & 1.24 \\
\hline $\begin{array}{l}\text { Muscarinic acetylcholine receptor MI } \\
\text { rs5098 I } 3 \text { ENST00000306960 }\end{array}$ & $\begin{array}{l}\text { GGCTTGGGCTCCT } \\
\text { CCCCCCAGCCAAC * } \\
\text { GGCTTGGGCTCCT } \\
\text { CCCGCCAGCCAAC }\end{array}$ & 0.21 & 0.11 & 0.08 & 0.05 & 0.09 & 0.70 & 0.60 & 0.46 & 0.46 & 0.37 & 4.11 \\
\hline $\begin{array}{l}\text { Follicle stimulating hormone receptor. } \\
\text { rs } 2882225 \text { ENST0000030442I }\end{array}$ & $\begin{array}{l}\text { GGCAAGGGAGCTG } \\
\text { TTTTTTTT } \\
\text { GGCAAGGGAGCTI } \\
\text { TTTTTTTT } *\end{array}$ & 1.10 & 1.00 & 0.86 & 0.71 & 0.75 & 1.96 & 1.73 & 1.67 & 1.36 & 1.35 & 1.80 \\
\hline $\begin{array}{l}\text { Adenosine-A3 receptor. rs } 1538251 \\
\text { ENST0000024I356 }\end{array}$ & $\begin{array}{l}\text { GGTGGCCACCAGA } \\
\text { GGGCAGCACG * } \\
\text { GGTGGCCACCAGA } \\
\text { GGGAAGCACG }\end{array}$ & 1.08 & 1.11 & 0.95 & 0.89 & 0.76 & 1.49 & 1.41 & 1.44 & 1.51 & 1.40 & 1.84 \\
\hline $\begin{array}{l}\text { Bradykinin receptor B2 rs } 1800508 \\
\text { ENST00000306005 }\end{array}$ & $\begin{array}{l}\text { GGGAAGTGCCCAG } \\
\text { GAGGC * } \\
\text { GGGAAGTGCICAG } \\
\text { GAGGC }\end{array}$ & 1.67 & 1.28 & 1.17 & 1.16 & 1.20 & 1.10 & 1.06 & 1.11 & 1.27 & 1.33 & 1.03 \\
\hline $\begin{array}{l}\text { Bradykinin receptor B2 rs945032 } \\
\text { ENST00000306005 }\end{array}$ & $\begin{array}{l}\text { GGTTCCTGGGTGC } \\
\text { GGG } * \\
\text { GGTTCCTGGGTAC } \\
\text { GGG }\end{array}$ & 0.88 & 0.72 & 0.72 & 0.62 & 0.55 & 1.15 & 1.22 & 1.29 & 1.22 & 1.27 & 2.30 \\
\hline $\begin{array}{l}\text { Bradykinin receptor B2 rs } 1799722 \\
\text { ENST00000306005 }\end{array}$ & $\begin{array}{l}\text { GGCTGGGTAGTGA } \\
\text { TGTCATCAGC } \\
\text { GGCTGGGTAATGA } \\
\text { TGTCATCAGC } *\end{array}$ & 0.36 & 0.21 & 0.16 & 0.12 & 0.12 & 0.50 & 0.29 & 0.22 & 0.20 & 0.20 & 1.66 \\
\hline $\begin{array}{l}\text { Calcitonin receptor precursor } \\
\text { rs252852 I ENST000003 I6576, } \\
\text { ENST00000248548 }\end{array}$ & $\begin{array}{l}\text { GGCTGTCCCCGGA } \\
\text { GTGGCGGCT } \\
\text { GGCTGTCCCCGGA } \\
\text { GTGACGGCT } *\end{array}$ & 0.54 & 0.36 & 0.25 & 0.22 & 0.21 & 0.90 & 0.83 & 0.73 & 0.60 & 0.55 & 2.62 \\
\hline
\end{tabular}

nature of TFBS modeling can be significantly remedied. Therefore we chose for this work, not to include 'negative controls', that is, SNPs from outside of mouse-human conserved regions. We do indeed think that larger studies in the future should perhaps incorporate certain number of such negative controls to validate the theoretical predictions. Thus, using PWMs it should be possible to overcome the difficulties with rSNP detection stated above.
We reasoned that if the score difference between alleles is large, it should correspond to a difference in gene expression that is reproducible in living cells. Using the JASPAR database of PWMs [27] and a phylogenetic footprinting strategy previously shown to be successful [17], we developed a method to detect putative TFBS and identify rSNPs likely to affect TF binding significantly. By incorporating phylogenetic footprinting, the method reported in this 


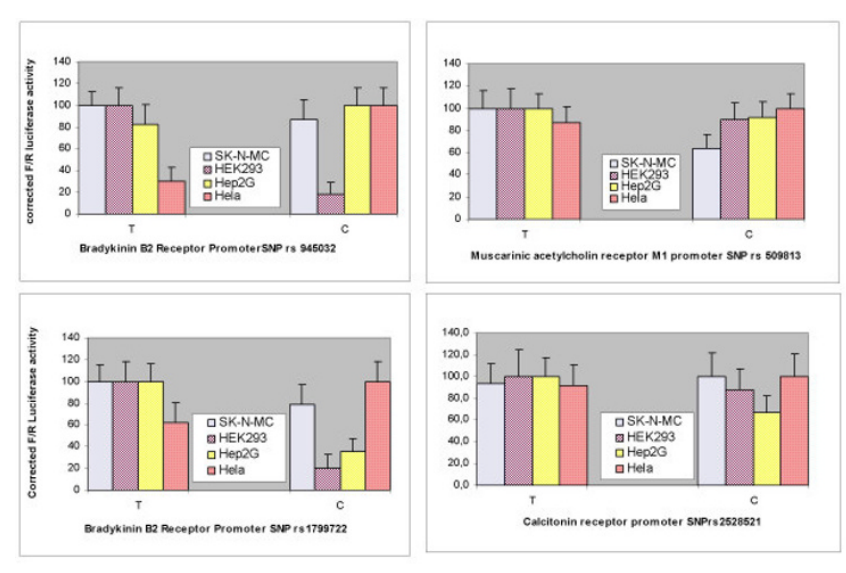

Figure 2

Comparative promoter activity in different cell lines. Influence of four functional promoter SNPs on promoter activity is dependent on cell types. Measurements are an average of four independent experiments. $A$ ' $T$ ' indicates an 'AA' and a ' $C$ ' indicates a 'GG' genotype.

study emphasizes SNPs present in genomic regions that are highly conserved between human and mouse, thereby increasing the probability of a downstream functional influence of variations within theses sequences.

Electromobility Shift Assays (EMSA) produce DNA-protein binding interactions in artificial conditions. Therefore in silico prediction methods based on other in vitro or in vivo selection technologies, like 'systematic evolution of ligands by exponential enrichment' (SELEX), may not agree with the experimental outcome of EMSA procedures. Since the construction of PWMs is often concluded from published records based on SELEX enrichment approaches, it is informative to experimentally validate the predicted binding site using methods like EMSA. Therefore, we validated a subset of our predictions with in vitro electro-mobility shift. We used a stringent selection criterion, that is, qualified only alleles demonstrating an absolute binding score difference of 2.0 or more. A stringent selection criterion would no doubt decrease excessive hits and false positives at the expense of certain loss of true positives. Our results showed that approximately $60 \%$ $70 \%$ (i.e. 7 out of the selected 10 SNPs) of predicted sites (Table 2) bind proteins from HeLa nuclear extracts.

We finally attempted to correlate the EMSA findings from the 10 SNPs with influences on actual promoter activity within living cells. Due to mapping discrepancies of one SNP and failure to clone one promoter, we tested only four out of the seven EMSA-positive SNPs identified thus far. Of the four SNPs tested in a promoter-less expression vector, two (rs945032 and rs1799722) indicated significant influence on promoter activity, while two showed convincing and reproducible, yet comparatively limited influence (rs2528521 and rs509813) on promoter activity. The influence of these polymorphisms (rs945032 and rs1799722) indicate that any given functional variation within a regulatory region might exert a measurable influence within the context of a cell type determined by the TF expression profile of the cells and perhaps competitive binding of the TF to overlapping multiple binding sites.

There are several factors in the current approach which indicate that there are far more rSNPs than currently detected using available technologies. The EMSA assays employ HeLa nuclear extract, thereby limiting our findings to the TF expression repertoire of only HeLa nuclei. The TFBS package used a limited collection of high quality PWMs, which unfortunately represent only a small part of the approximately 2,000 known human and mouse TFs. The theoretical thresholds set for selections of alleles which are predicted to differentially bind TF require further rigorous testing to ensure that the present selection is optimal.

\section{Conclusions}

From a total of approximately 200 SNPs in evolutionally conserved 5'-FR of 176 human GPCR genes, our prediction algorithm selected 36 SNPs with possible influence on TFBS. When ten of these 36 SNPs were tested for mobility shifts, seven exhibited a positive result, and four of these were further tested for influence on promoter activity using an in situ reporter system. Finally, two of the four showed significant and reproducible influences which were dependent on the cell environment. Thus starting from a large pool of potential regulatory SNPs, we successfully identified a small fraction that actually influenced promoter activity. We therefore propose a method for effective selection of functional, regulatory SNPs, in evolutionary conserved 5'-FR regions of human genes, as a means for identification of candidate SNPs for genetic association analysis studies.

\section{Methods \\ Sequence alignment and TFBS detection}

The GPCR genes were selected from Ensembl [25]. Human and mouse genome assemblies (versions hg12 and $m m 2$, respectively) and mappings of GenBank and RefSeq cDNA sequences to the assemblies were retrieved from the UCSC Genome Browser Database [26]. In addition, cDNA sequences for the 176 7TM or GPCR genes (online supplement) were mapped to the human genome assembly and 50,821 mouse cDNA sequences from the RIKEN project [29] were mapped to the mouse genome 
assembly using the client/server version of BLAT [30] with default settings. For each of the 176 GPCR-encoding human cDNAs, we retrieved the genomic mapping with the highest number of matching bases. Orthologous mouse loci were identified by similarly retrieving mouse genomic mappings for mouse cDNAs defined as orthologs to the human cDNAs in GeneLynx [31]. To more reliably identify transcriptional start sites we searched for other cDNA mappings overlapping the retrieved mappings and indicating similar gene structures. For each gene, the cDNA mapping extending furthest 5 ' was then used for further analysis. We extracted human genomic sequences from -5000 to +100 relative to starts of human cDNA mappings and mouse genomic sequences from -30000 to +100 relative to starts of mouse cDNA mappings. Orthologous genomic sequences were aligned using BLASTZ [32] with default settings. Aligned regions preceding human cDNA mappings were searched for putative rSNPs as follows. SNP data for the human genomic regions was retrieved from dbSNP, build 114 . For each SNP within an aligned region, two allelic versions of a 110-bp alignment slice centered around the SNP were searched for putative TFBS using the TFBS Perl modules [33] and all position-weight matrices in the JASPAR database describing vertebrate TFBS and having an information content of at least 7 [27]. Hits fulfilling the following 3 criteria were considered putative TFBS: (a) situated within regions of at least $70 \%$ sequence identity (conservation) over 50 base pairs; (b) situated at corresponding (aligned) positions in human and mouse sequences; (c) having a relative matrix score of at least 0.5 in both human and mouse sequences. Selected for further analysis were putative TFBS with a relative matrix score exceeding 0.8 in one of the human alleles and either undetected in the other allele or having a difference in absolute matrix score of at least 2 between the human alleles.

\section{Electromobility Shift Assays (EMSA)}

Table 2 lists the sequences of oligonucleotides used for EMSA tests. For setting up of EMSA experimental procedures, an earlier published positive shift assay was reproduced using a polymorphism in the gene MMP12 [34]. Method modifications were then applied as described below.

Double stranded oligonucleotides were synthesized with 5'-GG dinucleotide overhangs. The 3'-end of the complementary strand was labeled with [ $\left.\alpha^{32} \mathrm{P}\right]$ dCTP with fill-in reaction using Klenow flagment. The labeled oligonucleotide were passed through ProbeQuant G-50 Micro Columns (Pfizer-Pharmacia Inc) and the concentration was adjusted to $0.035 \mathrm{nM}$. A $0.8 \mu \mathrm{l}$ volume portion was mixed with $1.6 \mu \mathrm{l} \mathrm{HeLa} \mathrm{Nuclear} \mathrm{Extract} \mathrm{(Promega}{ }^{\mathrm{TM}}$ ), $1.6 \mu \mathrm{l} 5 \mathrm{x}$ Gel Shift Binding 5x Buffer (Promega ${ }^{\mathrm{TM}}$ ), and $3.2 \mu \mathrm{l}$ water.
After 10 min incubation at room temperature, $0.8 \mu \mathrm{l}$ of non-labeled competitor DNA, either one allele or the other allele, was added in varying concentrations (5-, 10-, $15-, 20$ - and 25 -folds greater than the radio-labeled oligonucleotide). After $20 \mathrm{~min}$ room temperature incubation, the entire $8 \mu \mathrm{l}$ reaction was loaded on polyaclylamide gel (5\% $22.5 \mathrm{mM}$ Tris/22.5 mM boric acid/0.5 mM EDTA buffer in, BIO RAD ${ }^{\mathrm{TM}}$ ). Thereafter, electrophoresis was performed in TBE for $20 \mathrm{~min}$ at $200 \mathrm{~V}$. Gels were placed on Whatmann $3 \mathrm{MM}^{\mathrm{TM}}$ filters and to facilitate drying a BIO $\mathrm{RAD}^{\mathrm{TM}}$ gel-dryer was used for 30 minutes. The dried gel were exposed to intensifying screen and analyzed by Typhoon Image Analyzer 9400 (Pfizer-Pharmacia Inc ${ }^{\mathrm{TM}}$ ).

\section{Sequencing and RFLP (Restriction fragment length polymorphism)}

The frequency of Dopamine receptor D1 polymorphism rs267413 was determined by sequencing a 174 base-pair fragment of the promoter in 10 DNA samples from healthy Swedish individuals. The sequence of the forward primer used for PCR was 5'-GGGGTACCACTTGACCGTTCTGTTGCTTT-3' where a KpnI restriction site (GGTACC) and GG-dinucleotide was added to the $5^{\prime}$ end. The sequence of the reverse primer was 5'-TCTTTTAAGCTCTACTGTGGGTGA-3'. Calcitonin receptor promoter polymorphism rs2528521 was analyzed by RFLP (fragment length was $334 \mathrm{bp}$, restriction enzyme Tsp45I). Forward primer sequence used for PCR was 5'-ACCCCCAAGGTGTCTCTTCT-3' and reverse primer: 5'- GAGGGACCCGAGTTAGACCT-3'. The primer sequences for Bradykinin promoter SNP rs1799722 were as follows: Forward primer 5'-CCAGGAGGCTGATGACGTCA-3'. The fourth base from 3 '-end was changed from A to $G$ from original genomic sequence to create a Tsp45I restriction site for RFLP analysis.

Reverse primer: 5'-TCAGTCGCTCCCTGGTACTG-3'. Fragment length amplified was $150 \mathrm{bp}$. PCR conditions for all RFLP and sequencing reactions were as follows: $94 \mathrm{C}(4$ $\mathrm{min})$, followed by 42 cycles of $94 \mathrm{C}(1 \mathrm{~min}), 61 \mathrm{C}$ (30 sec) and $72 \mathrm{C}(30 \mathrm{sec})$.

\section{Luciferase expression system for promoter activity analysis} A promoter-less luciferase vector (Basic PGL3, Promega ${ }^{\mathrm{TM}}$ ) was used for cloning known promoter regions between restriction sites $K p n I$ and $B g l I I$ of the plasmid vector. Primers for CHRM1: Forward: 5'-GGGGTACCGCAGGACCCACATCTCTAGG-3' Reverse ${ }^{\prime}$ = ${ }^{\prime}$ GAAGATCTTCACCAGGGCACCCAAT-3'. Primers for BK2: Forward $=5$ '-GGGGTACCATCTGAGACTCTGTTTCCC$3^{\prime}$ reverse $=5^{\prime}$-GAAGATCTTTCAGTCGCTCCCTGGTACT3'. Primers for CT-R: Forward $=5$ '-GGGGTACCCCTTGGAATCAACTTGCCT-3' reverse $=5^{\prime}$ '-TTCTCGAGCGTCCTTGGAATCAACTTGC-3'. Genomic DNA of 27 individuals of Nordic origin were amplified and 
sequenced to identify the genotype of sample DNA. Cloned DNA were sequenced by using primer set GLprimer2 : 5'-CTAGCAAATAGGCTGTCCC-3' and 5'CTTTATGTTTTTGGCGTCTTCC-3'. HeLa cells were plated in 24 well plates one day before transfection in appropriate medium with serum without antibiotics. Basic PGL3 Plasmids containing the cloned promoter region (180 ng) were co-transfected with 20 ng of pRL-TK plasmid, using Lipofectamine 2000 (Invitrogen $^{\mathrm{TM}}$ ). Luciferase activities were determined using a dual Luciferase Reporter Assay system (Promega ${ }^{\mathrm{TM}}$ ) according to the manufacturer's instructions.

\section{Abbreviations}

TF: Transcription Factor; TFBS: transcription factor binding site; SNP: Single Nucleotide Polymorphism; GPCR: Gprotein coupled receptors; 5'-FR: 5' flanking regulatory region.

\section{Authors' contributions}

Original Concepts and supervision: CW, WWW, BL and SM-T; Bioinformatics: PGE, BL and SMT; Running costs: SMT and CW; Manus preparation: SMT, PGE, CW; Electromobility Shift Assays and RFLP assays: YM; Luciferase expression: MAF and YM.

\section{Additional material}

\section{Additional File 1}

ENSG ids A list of 176 initial GPCRs considered for this study, along with the Ensembl ENSG Ids.

Click here for file

[http://www.biomedcentral.com/content/supplementary/14712164-6-18-S1.txt]

\section{Additional File 2}

Alignments Alignment information for sequence flanking rs945032 and rs1799722 in human and mouse.

Click here for file

[http://www.biomedcentral.com/content/supplementary/14712164-6-18-S2.txt]

\section{Acknowledgments}

This work was supported by Pfizer Inc. and by the Swedish National Research Foundation. We would like to express our thanks to Dr. Madis Metsis for his technical advice and unbiased analysis of the EMSA results and to Dr. Albin Sandelin for valuable discussion.

\section{References}

I. Brookes AJ, Lehvaslaiho H, Siegfried M, Boehm JG, Yuan YP, Sarkar CM, Bork P, Ortigao F: HGBASE: a database of SNPs and other variations in and around human genes. Nucleic Acids Res 2000, 28:356-360.

2. Cargill M, Altshuler D, Ireland J, Sklar P, Ardlie K, Patil N, Shaw N, Lane CR, Lim EP, Kalyanaraman N, Nemesh J, Ziaugra L, Friedland L, Rolfe A, Warrington J, Lipshutz R, Daley GQ, Lander ES: Character- ization of single-nucleotide polymorphisms in coding regions of human genes. Nat Genet 1999, 22:231-238.

3. Chasman D, Adams RM: Predicting the Functional Consequences of Non-synonymous Single Nucleotide Polymorphisms: Structure-based Assessment of Amino Acid Variation,. Journal of Molecular Biology 200I, 307:683-706.

4. Ramensky V, Bork P, Sunyaev S: Human non-synonymous SNPs: server and survey. Nucl Acids Res 2002, 30:3894.

5. Sunyaev S, Ramensky V, Bork P: Towards a structural basis of human non-synonymous single nucleotide polymorphisms. Trends in Genetics 2000, 16:198-200.

6. Sunyaev S, Ramensky V, Koch I, Lathe III W, Kondrashov AS, Bork P. Prediction of deleterious human alleles. Hum Mol Genet 200 I, I 0:59|.

7. Sherry ST, Ward MH, Kholodov M, Baker J, Phan L, Smigielski EM, Sirotkin K: dbSNP: the NCBI database of genetic variation. Nucleic Acids Res 200 I, 29:308-3II.

8. Ponomarenko JV, Merkulova TI, Orlova GV, Fokin ON, Gorshkova EV, Frolov AS, Valuev VP, Ponomarenko MP: rSNP_Guide, a database system for analysis of transcription factor binding to DNA with variations: application to genome annotation. Nucleic Acids Res 2003, 3 I : I 18-121.

9. Pennacchio LA, Rubin EM: Genomic strategies to identify mammalian regulatory sequences. Nat Rev Genet 2001, 2:100-109.

10. Stormo GD: DNA binding sites: representation and discovery. Bioinformatics 2000, 16:16.

II. Fickett JW: Quantitative discrimination of MEF2 sites. Mol Cell Biol 1996, 16:437.

12. Fickett JW: Predictive methods using nucleotide sequences. Methods Biochem Anal 1998, 39:231-245.

13. Workman CT, Stormo GD: ANN-Spec: a method for discovering transcription factor binding sites with improved specificity. Pac Symp Biocomput 2000:467-478.

14. Tronche F, Ringeisen F, Blumenfeld M, Yaniv M, Pontoglio M: Analysis of the Distribution of Binding Sites for a Tissue-specific Transcription Factor in the Vertebrate Genome,. Journal of Molecular Biology 1997, 266:23 |-245.

15. Duret L, Bucher P: Searching for regulatory elements in human noncoding sequences. Curr Opin Struct Biol 1997, 7:399-406.

16. Krivan W, Wasserman WW: A Predictive Model for Regulatory Sequences Directing Liver-Specific Transcription. Genome Res 200I, I I:I559.

17. Lenhard B, Sandelin A, Mendoza L, Engstrom P, Jareborg N, Wasserman WW: Identification of conserved regulatory elements by comparative genome analysis. J Biol 2003, 2: I3.

18. Loots GG, Locksley RM, Blankespoor CM, Wang ZE, Miller W, Rubin $\mathrm{EM}$, Frazer KA: Identification of a coordinate regulator of interleukins 4, 13 , and 5 by cross-species sequence comparisons. Science 2000, 288: I36-I40.

19. Shabalina SA, Ogurtsov AY, Kondrashov VA, Kondrashov AS: Selective constraint in intergenic regions of human and mouse genomes. Trends Genet 200I, I 7:373-376.

20. Rubin GM, Yandell MD, Wortman JR, Gabor Miklos GL, Nelson CR, Hariharan IK, Fortini ME, Li PW, Apweiler R, Fleischmann W, Cherry JM, Henikoff S, Skupski MP, Misra S, Ashburner M, Birney E, Boguski MS, Brody T, Brokstein P, Celniker SE, Chervitz SA, Coates D, Cravchik A, Gabrielian A, Galle RF, Gelbart WM, George RA, Goldstein LS, Gong F, Guan P, Harris NL, Hay BA, Hoskins RA, Li J, Li Z, Hynes RO, Jones SJ, Kuehl PM, Lemaitre B, Littleton JT, Morrison DK, Mungall C, O'Farrell PH, Pickeral OK, Shue C, Vosshall LB, Zhang J, Zhao Q, Zheng $\mathrm{XH}$, Lewis S: Comparative genomics of the eukaryotes. Science 2000, 287:2204-2215.

2I. Muller G: Towards 3D structures of $\mathbf{G}$ protein-coupled receptors: a multidisciplinary approach. Curr Med Chem 2000, 7:861-888.

22. Rana BK, Shiina T, Insel PA: Genetic variations and polymorphisms of $\mathbf{G}$ protein-coupled receptors: functional and therapeutic implications. Annu Rev Pharmacol Toxicol 2001, 41:593-624.

23. Sadee W, Hoeg E, Lucas J, Wang D: Genetic variations in human $\mathbf{G}$ protein-coupled receptors: implications for drug therapy. AAPS PharmSci 2001, 3:E22.

24. Small KM, Seman CA, Castator A, Brown KM, Liggett SB: False positive non-synonymous polymorphisms of G-protein coupled receptor genes. FEBS Letters 2002, 5 I 6:253-256. 
25. Hubbard T, Andrews D, Caccamo M, Cameron G, Chen Y, Clamp M, Clarke L, Coates G, Cox T, Cunningham F, Curwen V, Cutts T, Down T, Durbin R, Fernandez-Suarez XM, Gilbert J, Hammond M, Herrero J, Hotz H, Howe K, lyer V, Jekosch K, Kahari A, Kasprzyk A, Keefe D, Keenan S, Kokocinsci F, London D, Longden I, McVicker G, Melsopp C, Meidl P, Potter S, Proctor G, Rae M, Rios D, Schuster M, Searle S, Severin J, Slater G, Smedley D, Smith J, Spooner W, Stabenau A, Stalker J, Storey R, Trevanion S, Ureta-Vidal A, Vogel J, White S, Woodwark C, Birney E: Ensembl 2005. Nucleic Acids Res 2005, 33 Database Issue:D447-D453.

26. Karolchik D, Baertsch R, Diekhans M, Furey TS, Hinrichs A, Lu YT, Roskin KM, Schwartz M, Sugnet CW, Thomas DJ: The UCSC Genome Browser Database. Nucleic Acids Res 2003, 3 I:5 I-54.

27. Sandelin A, Alkema W, Engstrom P, Wasserman WW, Lenhard B: JASPAR: an open-access database for eukaryotic transcription factor binding profiles. Nucleic Acids Res 2004, 32 Database issue:D91-D94.

28. Okazaki Y, Furuno M, Kasukawa T, Adachi J, Bono H, Kondo S, Nikaido I, Osato N, Saito R, Suzuki H: Analysis of the mouse transcriptome based on functional annotation of 60,770 fulllength cDNAs. Nature 2002, 420:563-573.

29. Kent WJ: BLAT - the BLAST-like alignment tool. Genome Res 2002, I 2:656-664.

30. Lenhard B, Hayes WS, Wasserman WW: GeneLynx: a gene-centric portal to the human genome. Genome Res 200I, II:2I5I-2I 57.

31. Schwartz S, Kent WJ, Smit A, Zhang Z, Baertsch R, Hardison RC, Haussler D, Miller W: Human-mouse alignments with BLASTZ. Genome Res 2003, 13:103-107.

32. Lenhard B, Wasserman WW: TFBS: Computational framework for transcription factor binding site analysis. Bioinformatics 2002, I 8: I I35-II36.

33. Jormsjo S, Whatling C, Walter DH, Zeiher AM, Hamsten A, Eriksson P: Allele-specific regulation of matrix metalloproteinase-7 promoter activity is associated with coronary artery luminal dimensions among hypercholesterolemic patients. Arterioscler Thromb Vasc Biol 2001, 21:1834-1839.

Publish with Biomed Central and every scientist can read your work free of charge

"BioMed Central will be the most significant development for disseminating the results of biomedical research in our lifetime. "

Sir Paul Nurse, Cancer Research UK

Your research papers will be:

- available free of charge to the entire biomedical community

- peer reviewed and published immediately upon acceptance

- cited in PubMed and archived on PubMed Central

- yours - you keep the copyright

Submit your manuscript here:

http://www.biomedcentral.com/info/publishing_adv.asp
BioMedcentral 